\title{
Ideologies and Attitudes towards Pidgin English in Cameroon
}

\author{
Jane-Francis Afungmeyu Abongdia
}

University of Fort Hare

jabongdia@ufh.ac.za

\section{Doi:10.5901/mjss.2014.v5n7p601}

\begin{abstract}
The major focus of this paper is an examination of the role of lingua francas in Cameroon. It examines how Cameroon Pidgin English (CPE) functions within a bilingual country with about 280 indigenous languages. The CPE finds expression in the ways in which the language policy has been developed and implemented across the country with two official languages: English and French. The paper considers the nature of ideologies and attitudes and their development as a result of the socio-ecomonic and political position of English and French in Cameroon as well as the role of the CPE in this bilingual context.
\end{abstract}

Keywords: Lingua franca, language ideologies, language attitudes, Cameroon, English, French, indigenous language, bilingualism.

\section{Introduction}

This paper examines language ideologies and attitudes towards Cameroon Pidgin English at the University of Yaoundé I in Cameroon. Cameroon is a linguistically diverse country with about 280 languages spoken (Anchimbe 2006). This paper critically examines the use of the Cameroon Pidgin English (CPE) among university students and lecturers are the University of Yaoundé 1 in Cameroon. This university was chosen because it is the first state owned university with a bilingual language policy. Being a microcosm of the macrocosm (Cameroon) one would not only expect the official language of the country to be prominent but also the country's lingua franca (CPE). Thus the need to investigate the role of the language and the different ideologies and attitudes Cameroonians in general and students and lecturers in particular hold towards this language variety.

\section{The Aims of this Paper}

- to discuss some of the dominant ideologies and attitudes held towards CPE at the University of Yaoundé 1 in Cameroon

- to divulge the role this language variety has in the Cameroonian society in general and the University of Yaoundé 1 in particular.

\section{Background}

Cameroon was founded around 1472 by a Portuguese navigator, Fernando Po. When Germany colonised Cameroon in 1884, the country was named Kamerun which later changed to "Cameroon" and "Cameroun" during the British and French rules respectively (Echu 1999). When Germany lost the First World War in 1918, its colonial possessions were handed over to the victors, France and Britain. The Cameroonians were then expected to speak French and English, but this was impossible as they did not know the languages and had to learn them for the first time. However, by the 1950s, there was agitation for reunification by both sides. In 1961, through a plebiscite, the Federal Republic of Cameroon was born. In the Federal Republic of Cameroon there was now the language problem given that two languages were inherited: French and English. French was used by four-fifths of the country and English by the remaining fifth (Fonlon 1969). The 1961 constitution stated that French and English were the official languages: French for the Federal state of East Cameroon and English for that of West Cameroon. For fear of future tension from any of the groups, French and English were adopted as the official languages of Cameroon. To further confirm this choice, bilingualism in these two languages was recommended. The adoption of French and English as the official languages in Cameroon gave rise to two distinguishing linguistic markers: Francophone and Anglophone Cameroonians. French became the lingua franca in the French speaking part of Cameroon and Cameroonian Pidgin English (CPE) in the English speaking part. The 
development of these two linguistic communities has rather attenuated than solved the linguistic problem in Cameroon (Mforteh 2006).

The University of Yaounde 1 is the oldest state-owned university in Cameroon created in 1962 by presidential decree and with the help of the French government as the Federal University of Yaoundé. It has a bilingual language policy and caters for both the Anglophones and Francophones. In spite of these strategies, the policy of effective FrenchEnglish bilingualism is not a success in Cameroon. The problem may lie in the very monolingual orientation of the policy, which sees these languages as distinct, separate entities, and makes no room for blended varieties like CPE, Camfrananglais or even indigenous languages. In addition, the so-called Anglophone population is much smaller than the Francophone one, leading to the dominance of Cameroonian French in virtually all government departments, businesses and public offices. This socio-political reality therefore means that there are different ideological perspectives on the two official languages as well as the CPE and the indigenous languages in Cameroon. However, English, like French, is going through a structural nativisation (Nkemleke, 2008) and (standard) English language proficiency is declining among Cameroonians, who mainly use indigenised Englishes or what is called Cameroon English (CamE) or Anglophone English (AngE) (Fontem et al., 2008, Simo Bobda \& Mbangwana, 1993).

Moreover, it was noted that the ethnolinguistic boundaries are increasingly being crossed over and becoming diffused as a result of the increased use of CPE as a lingua franca and the urban youth variety called Camfran-anglais. For some people, CPE, which is actually a creole rather than a pidgin, is actually their first language (Ayafor 2006). CPE originated as a pidgin in the $18^{\text {th }}$ century when traders and missionaries came to West Africa. After the abolition of the slave trade, CPE continued to expand all over the coastal region and was widely used by workers in the Cameroon Development Corporation (CDC), as it was the only language that could facilitate communication. With the birth of the Federal Republic of Cameroon in 1961, CPE grew in terms of its vocabulary, idiom and structure because of the influence of French and the other local languages spoken by the Francophones (Echu 2003). In the mid-sixties, $85 \%$ of CPE terms came from English, 13\% from the indigenous languages and 2\% from other languages including Portuguese and German (Echu 2003: 4). Ten years later, 80\% of CPE words were English-based, 14\% came from indigenous languages, 5\% from French and 1\% from other languages (Echu 2003).

As far as the Cameroon Pidgin English (CPE) is concerned, it is largely spoken in the two English speaking regions of Cameroon and to some extent in the littoral and western regions. However, Menang (2006: 232) contends that English had long been in use along the Guinea Coast for many years before Cameroon became a political entity following its annexation by the Germans in 1884. When commercial activities were intensified by the English, Pidgin English gained more grounds in this country as the main medium of commercial transactions. This became the main language used in the plantations and the workers later on carried it back to their different areas of origin.

Cameroonians in these two regions have over the years used Pidgin English as a marker of their identity. Even pre-school children in these regions have a good mastery of Pidgin English and only gain a mastery of formal English later at school. According to Mba (2011: 3) many children more often than not have Pidgin as their mother tongue at the expense of the mother tongue of their parents, as Pidgin is used in buying and selling, in religious teaching and worship, in home interaction, in out-group communication and in cultural expression. It should be noted that this language variety is also used by the educated as they constantly switch to Pidgin in verbal interactions.

Currently, there are two varieties of CPE: the Anglophone variety and the Francophone one. CPE is now being used in all functional domains in the country such as in churches, in the markets, on the streets, by teachers in class to make explanations easier for their learners, and also used by writers. It is even used as the first language (L1) in crosslinguistic, cross-cultural families. Despite its popularity, its use is frowned upon by many who believe that its use will prevent people from acquiring the desired standard in the two official languages. For example, at the University of Buea, the following criticisms of CPE appear on certain notice-boards:

\author{
English is the password not Pidgin \\ English is the language of Commonwealth, not Pidgin \\ If you speak pidgin, you'll write pidgin \\ Pidgin is taking a negative toll on your English; shun it (Ayafor 2006: 197)
}

It should be noted that Cameroonian Pidgin English (CPE) functions as a common language, spoken by people from divergent backgrounds and social classes. 


\section{Methodological Consideration}

The qualitative data for this paper was collected through the use of open-ended questions on questionnaires, face-to-face interviews, as well as observations. The data was obtained from lecturers and students at the University of Yaoundé 1: Cameroon.

The data for this study was collected thus:

1. Questionnaires were completed by (60) students and (15) lecturers

2. Individual interviews were conducted with selected lecturers and students.

3. Observation was done on the use of the different language varieties by the different groups (students and lecturers) within the university.

The students used in this study were third year Linguistic students while the lecturers came from both the linguistic and English departments.

\section{Theoretical and Conceptual Framework}

This paper examines the notions of language ideologies and language attitudes towards the Cameroon Pidgin English in a diverse multicultural and multilingual modern era. While there is considerable overlap between the descriptions of language ideologies, this paper will focus on the ways in which sociolinguists approach this concept. Weber and Horner (2012: 16) define language ideology as the "cultural system of idea and feelings, norms and values, which inform the way people think about language". They refer to Kroskristy's (2000) concept of language ideology as representative of perceptions of a language or discourse "constructed in the interest of a specific social group: they are multiple rather than fixed or unitary; people usually display varying degrees of awareness of these language ideologies; and language ideologies mediate between social structures and forms of talk" (Weber and Horner 2012: 16). Weber and Horner (2012: 16-20) list five major language ideologies:

- There is a language hierarchy - language uses can be labelled and divided into 'languages' or 'dialects', 'patois', etc. , with 'languages' enjoying the highest status. Some languages also enjoy a higher status than others when they are labelled national or official languages;

- The standard language ideology (Milroy and Milroy 1999) - based on the belief that languages are internally homogenous, bounded entities, with a certain variety chosen for standardisation simply because of sociopolitical movements, and definitely not because of any inherent superiority of these varieties over others;

- The ideology of language purism, which stipulates what constitutes 'good' and 'bad' language usage, and often appears in times of rapid social change;

- The one-nation one-language ideology, which makes language equal to territory and national identity; and

- The mother-tongue ideology, which believes that speakers only have one mother-tongue.

Weber and Horner (2012) conclude that the fear of linguistic heterogeneity and ideologies of purism are not just ideas and attitudes about language but are translated into practices that can lead to social consequences for the entire community. They see languages as determined by socio-political factors rather than purely linguistic ones, resulting in languages being social constructs - means of social interaction.

According to Myers-Scotton (2006) language ideology focuses on the legitimacy of the status between competing groups, and invariably favours the dominant group over the minority group. She holds that globalization has an effect on national languages, by promoting "the increasing power of various languages that are already established as the languages of wider communication" (Myers-Scotton 2006: 136). She however thinks that although language ideology can cause people to lose their national languages, it can in some cases help to maintain these languages. This can happen in situations where people believe that certain fixed cultural ceremonies can only be performed in particular languages. She therefore concludes that language ideologies are perceptions of how different language varieties are used in the interests of a particular group of people, making it a system of belief. The group in power impose its values, including its linguistic values on the other, and this implies that a person's linguistic repertoire is also in line with Bourdieu's notion of social capital (Bourdieu 1991), a source of symbolic power.

Language Ideologies cannot be discussed without also considering the closely related field of Language Attitudes. According to Dyers and Abongdia (2010) studies in language ideologies and language attitudes overlap in the two areas:

1. Both of them deal with the issue of status and how this affects patterns of language shift and maintenance in societies. Schiffman (1997) lists a number of language attitude studies on the status of a language, the status of its speakers or the status of the variety (standard/non-standard) of the language, or its use in certain 
domains. Agheyisi and Fishman (1970) list language attitude studies that deal with the social significance of language or language varieties and attitudes towards speakers of different languages in multilingual settings.

2. Just as there are, according to Kroskrity (2000), a multiplicity of language ideologies which effectively capture social divisions within sociocultural groups, so language attitudes also tend to differ depending on factors like age, gender, social class and level of education, as has been shown in the studies conducted by Siachitema (1985), Morgan (1993) and Gardner and Maclntyre (1993).

If we consider the studies on language ideologies, one will have to concur with Dyers and Abongdia (2010) that language attitudes and language ideologies differ fundamentally in only one main area:

Ideologies are constructed in the interest of a specific social or cultural group: i.e. they are rooted in the socioeconomic power and vested interests of dominant groups. It can however also be seen how subordinated groups on whom such ideologies are imposed over time start to accept them as 'normal' patterns of behaviour. The use of English and French as medium of instruction and also as an official language is a good example in Cameroon. However, it is important to note that subordinate groups also have their own ideologies, and may develop counter-discourses to the ideologies of the powerful.

Another significant difference between the two concepts is that attitudes come from individuals (as in this study) while ideologies find expression in societies as the framework in which more personal attitudes are formed. Thus one could argue that language attitudes are often openly expressed by individuals, while language ideologies are made visible through language practices and policies. Emotion plays an important role in the expression of language attitudes. Pavlenko (2002) holds that the speakers have a preferred language for strong emotional expression (especially anger) which is always their first language (L1).

According to Pavlenko (2002), language attitudes are gradually being replaced as a field of research by language ideologies. To her, attitudes towards a language can be criticised and changed if the language affects the people positively (in obtaining better jobs and education as well as the opportunity to travel). She thinks that people with integrative motivation for learning a language (which implies a deep identification with the target language as well as speakers of a particular language) should be seen as having a particular ideology about that language, instead of an attitude. This is because one can interpret a person's language ideology as being related to political, cultural, social or economic improvement rather than a mere idea of identifying with the language and with the speakers of that language. Ideologies are therefore social constructions, but attitudes relate more to the construction of people's individual and even group identities. Thus, people may hold a particular attitude towards a language because they want to be identified with that language.

Language is one of the fundamental means through which we establish our identity and shape ourselves. Social groups and communities use language to identify their members and establish their boundaries (Myers-Scotton 2006 and Thomas et al. 2004). Thus, language is an important instrument for the construction of individual and social identities. Like dress codes that display people's membership to a social group, there are also certain kinds of linguistic behaviours that signal people's identity in relation to a group as well as their positions within it (Thomas et al. 2004). According to Baker (2006: 136), when we speak a language, it often identifies our origins, history, membership and culture. He says that "our identity is conveyed in our language, in our expressions and engagements, predilections and preference. Language is a symbol of unity, conveying our preferred distinctiveness and allegiance". He holds that our identities are reframed, developed and sometimes challenged as situations change. This is because we do not establish our identities by ourselves. Baker (2006) holds that some people hate to be called members of a minority language group because, like the concepts 'minority ethnic group' and 'cultural minorities', it carries a negative stigma, implying that the language and its speakers have less status than those of the majority group, who would also be less inclined to learn the minority language.

\section{Findings and Discussion}

\subsection{Open-ended questions in questionnaires}

This study investigated the role and status of Cameroon Pidgin English (CPE) and the ideologies and attitudes people hold towards these languages. This language variety, as mentioned earlier, is used as a lingua franca in Cameroon. Given the multilingual nature of this country (280 indigenous languages) with only two official languages, people communicated across linguistic borders via the use of CPE. The minority number of users of this language already give it the negative stigma echoed by Baker (2006), giving the language and its speakers less status than those of the majority group. It should be noted that stigma does not only remain with the CPE but is carried over to Camfran-anglais (CFA); a 
hip-hop language variety born from CPE, English and French. This is a language used by people who are not fluent or struggle with both English and French. It is a mixture of English and sometimes pidgin. While young people saw the use of this variety as a mark of being trendy and 'cool', most parents called it a language of gangsters and an inferior language like English (Ayafor 2006).

Considering the wide-spread use of CPE among students in this university, the biggest question was why this language had not been developed and used more widely in education. Of the students who responded to open-ended questions on CPE, $73.3 \%$ reported being able to communicate in both CPE and CFA, while the remaining $26.7 \%$ wrote responses like:

"I don't like them because it spoils our English and French languages".

"According to me, these varieties kill the language because the spread of these varieties tend to influence these languages. Initially, the creation of these varieties was to facilitate communication and interacting between different linguistic groups but this bad usage has transformed it into a dangerous thing".

"I don't speak these varieties because I don't like them". I am unhappy with it"

"I think it is not a good thing because those who speak those languages end up mastering neither English nor French".

The above responses reflected the common reasons why Cameroonians particularly the emerging middle class encouraged their children not to speak CPE, and can be related to Blommaert's (2006) view of how language ideologies become entrenched within the wider society. They felt that this variety interfered in the English language and the children may end up speaking 'poor English' or non-Standard English as was seen above. These students used words like 'spoil', 'kills', 'death' 'do like' to name a few. Three separate language ideologies (Weber and Horner 2012: 16-22) are clearly reflected here: an ideology of a hierarchy of language, where different varieties can be labelled and divided into 'languages' or 'dialects', 'patois', etc., with 'languages' enjoying the highest status - in this case, French and English over CPE. Weber and Horner also cite the standard language ideology (Milroy and Milroy 1999), where a certain variety is chosen for standardisation simply because of socio-political movements, and definitely not because of any inherent superiority of these varieties over others, as well as an ideology of language purism, which stipulates what constitutes 'good' and 'bad' language usage.

However, very few people in Cameroon actually speak Standard English (defined in exogenous standard norms), while the use of CPE is very common. Despite this, even at the University of Buea, an English university in Cameroon, there were billboards prohibiting the use of CPE on campus (Ayafor 2006).

Unlike the above students (26.7\%) who thought that using CPE and or Camfran-anglais was not a good idea, a majority of the students enjoyed using it and said it was important especially in a multilingual setting like Cameroon. Some of the responses from the questionnaires were:

\footnotetext{
"I feel at ease when speaking these varieties, it is more fluent and it develops familiarity and assurance amongst the speakers".

"These varieties should be used as a lingual franca just for communication between people from different backgrounds and not in formal contexts".

"It's our identity".

"Good for people from different linguistics backgrounds".
}

These more positive attitudes showed that the use of CPE was a form of social identity (Pavlenko 2006, MyersScotton 2006) among Cameroonians especially the Anglophones. For many, CPE was a language of intimacy, socialization and identification. It is used across linguistic boundaries in this country as well as for better understanding and self-expression. Mbangwana (1983: 87) highlights the importance of CPE in Cameroon as it is indispensable to Cameroonians irrespective of their educational status, linguistic background, etc. He says:

"Pidgin English is very crucial as a communication bridge, for it links an anglophone to a francophone. It also links an anglophone to another anglophone, an educated Cameroonian to another educated one, a non-educated Cameroonian to another non-educated one, and more importantly an educated Cameroonian to a non-educated one."

It is worth noting that even Cameroonians use this language as a form of group identity even outside the country. In fact, Thomas et al. (2004), Myers-Scotton (2006) and Pavlenko (2006) posit that people use languages to identify and negotiate their identities. Generally, when someone meets you for the first time and introduces him/herself as a Cameroonian, there is an immediate switch in codes from English to CPE and the moment the person cannot respond in this language, there is usually a doubt expressed if you are actually a Cameroonian especially if you are an Anglophone. 
Therefore, CPE is part of the identity among Anglophones in particular and Cameroonians in general.

As a follow-up to the above question, students were also asked if they thought this language variety (CPE) could be used to teach university subjects. A majority of them were negative about this as they thought that it could only be used for socialization in informal situations and nothing more. A major concern was the fact that this language was not used anywhere in the world for official purposes and would therefore not help them in any way. They cited its lack of development for use in education and its low status in the country. Responses included:

"No, it is degrading".

"No, they are not profitable; they make our English not to be clean".

Irrespective of these opposing views, a few of the participants (15\%) thought that CPE could be used for teaching and learning. The use of the word 'degrading' shows the negative stigma held towards CPE. It also reveals the notion of status echoed by Myers-Scotton (2006) where this language variety is seen as inferior and lower in status both nationally and internationally. included:

However, some of the students felt that this language variety could be used to teach at university. Their responses

"Yes, pidgin is satisfactory as it is a majority language".

"Yes, because it constitute codes of communication, but it would first and foremost be standardised".

According to these students, CPE is a language and can be used as well for teaching and learning. All that needed to be done was for the language to be standardised. Apart from the fact that the CPE was considered an inferior language in this setting, it was seen by Anglophones as the language of wider communication and intimacy (Ayafor 2006). Ghana also has their own versions of Pidgin English, which might follow the same potential trajectory of development as CPE over time and become used in more domains like universities.

\subsection{Interviews}

As was the case with the written responses to the open-ended questions on the use of Cameroon Pidgin English (CPE), some of the students interviewed also appeared to have positive attitudes towards this variety, as can be seen from the following responses:

\footnotetext{
"I think that for pidgin English for example in the North province, all grand mothers and fathers speak it, you cannot speak grammar with them, but the case of camfran-anglais is that, it is youth language to communicate and understand each other". (Francophone male student)

"It is good for socialization and familiarity". (Francophone male student)

"They are used when we are with friends or when we are in the family. They serve as means of creating an intimate relationship". (Anglophone male student)

"I think we should create our own languages which express properly what we are and our reality". (Anglophone male student)
}

The students in the interviews saw this language as a good variety for interpersonal socialization, and felt that it met many of the communicative needs of older and uneducated people. Interestingly, one of the students saw CPE as a language that reflects the people's reality much more than the ex-colonial languages could do. CPE reflected the ways in which people freely mix and blend any linguistic resources that were in their environment. This is similar to the languaging practices observed in many world cities, which, for Lytra and Jørgensen (2008: 5), captures the ways which people use "features of whatever ranges of languages they are exposed to in order to achieve their communicative purposes". Given the largely positive responses to the use of lingua franca in Cameroon, the government could consider making this language at least a national language on par with the pidgins similarly promoted in Nigeria, Sierra Leone and Ghana.

On the other hand, some of the students did not encourage the use of this language variety for different reasons.

"No, because it will spoil or destroy those students who are perfect in these languages".

"It is not the language of the world and therefore limits studies".

"There are no documents in these languages".

"No, it is good at home, market, churches, to be brief, our social life. But teaching it in schools will not be appreciated because it can't help in the international community". 
If one considers the responses above, it could be seen that the students felt that CPE had little or no value in their future lives. Some also felt that the use of CPE could have a negative influence on people's proficiency in English or French. These ex-colonial languages were given more value due to their international or global strength (Cameron 2001 and Pavlenko 2002). What can also be noted in the first example quoted here is the influence of the ideology of language purism as well as language hierarchies, as in the last example (Weber and Horner, 2012).

\subsection{Observation}

As far the CPE is concerned, a lot of the Anglophones used this variety for their interaction with one another as a language of socialisation. It should be noted that some students even used this language variety among them in lectures and during group studies. Although English is seen by most Cameroonians as 'bad English' that 'spoils' English proficiency, others prefer it as it gives them the room to express themselves even better than in English.

\section{Conclusion}

In CMR, the lingua franca is the Cameroon Pidgin English (CPE). The type of ideology held toward this language is a call for concern. Despite its widespread use and considerable vitality, CPE is seen as an inferior, uneducated, and primitive language in CMR and its use is frowned upon by those in authority.

Another ideology that emerged from this study was the negativity towards the use of Cameroonian Pidgin English (CPE). Many of the respondents felt that this language variety "spoiled", "killed", and "affected" the quality of English in the country despite the fact that it is fast "becoming a mother tongue in some urban communities" (Todd 1986: 68). Cameroonians generally view this language as the language for the uneducated, as it is "bad English" used only for informal communication. At least three of the language ideologies identified by Weber and Horner (2012) are reflected on the use of CPE: the ideologies of a hierarchy of languages, standard language and language purism.

\subsection{The hierarchy of languages ideology}

A dominant ideology was that of language hierarchy where some where people believed that some languages had a higher status than others (Weber and Horner 2012:16). English and French in Cameroon have a higher status over the indigenous languages and CPE. Akinnaso's (1991:41) ideology of assimilation, which forces people in Africa to use the dominant, ex-colonial language, can be tied to this language hierarchy.

\subsection{The standard language ideology (Milroy and Milroy 1999)}

The higher status accorded to standardized languages came up repeatedly. Some respondents held that only standardized languages should be used as medium of instruction while a variety such as the CPE in Cameroon was negatively stigmatized.

\subsection{The ideology of language purism}

This was particularly visible in the responses to the possible use of CPE in Cameroon. This is also the case in Nigeria as echoed by Akinnaso (1991: 41). At times, it appeared as if the ex-colonial languages were seen as the only "good" or "proper" languages (Weber and Horner 2012: 20).

Despite all the arguments that some languages are more developed, superior, inferior, dominant, minority or majority languages, there is no doubt that ideologies play a great role in people's language choices and thus, language policy makers can hardly ignore these when designing language policies.

\section{References}

Agheyisi, R. and Fishman, J. 1970. Language Attitude Studies. Anthropological Linguistics 12(5):137-157.

Akinnaso, N.F. 1991. Towards the development of a multilingual language policy in Nigeria. Applied linguistics 12(1): 29-61.

Anchimbe, E. A. 2006. Socio-pragmatic Constraints to Native or Indigenous Language Education in Cameroon. In Selected Proceedings of the 36th Annual Conference on African Linguistics. Somerville, MA: Cascadilla Proceedings Project.

Ayafor, M. 2006. Komtok (Pidgin) Gaining Ground in Cameroon. In Chia, N. E. (ed) African linguistics and the development of African 
communities (191-199). UK: Oxford University Press.

Baker, C. 2006. Foundations of Bilingual Education and Bilingualism. Clevedon: Multilingual Matters

Blommaert, J. 2006. Language policy and national identity. In Ricento, T. (ed.) An introduction to language policy: theory and method. Oxford: Blackwell Publishing.

Bourdieu, P. 1991. Language and Symbolic Power. Cambridge, MA: Harvard University Press.

Cameron, D. 2001. Current Debates on Language and Globalization, Faculty Seminar Fall.

Dewaele, J. M. 2004. Perceived language dominance and language preference for emotional speech: The implications of attribute research. In Schmind, M.S., Kejser, M. and Weilemar, L. (eds.) First Language Attribution: Interdisciplinary Perspectives on Methodological Issues. Amsterdam: John Benjamins(81-104).

Dyers, C. and Abongdia, J. 2010. An Exploration of the Relationship between Language Attitudes and Ideologies in a study of Francophone learners of English in Cameroon. Journal of Multilingual and Multicultural Development 31(2):119-134.

Echu, G. 1999. Colonialism and Linguistic Dilemma in Africa: Cameroon as a Paradigm (Revisited) Quest. X111:1 -2.

Echu, G. 2003. Coping with Multilingualism: Trends in Evolution of Language Policy in Cameroon. Online: http:///web.fuberlin.de/phin/phin25/p25t2.htm retrieved 07/09/07

Fonlon, B. 1969. The Language Problem in Cameroon: A Historical Perspective. ABBIA 22: 5-40.

Fontem, A. N. and Oyetade, S.O. 2008. "Declining Anglophone English language proficiency in Cameroon: What factors should be considered?" In Chia, E. N., Tala, K. I. and Jick, H. K. (eds.) Globalisation and the African Experience: Implications for Language, Literature and Education. Limbe, Cameroon: ANUCAM Publisher.

Gardner, R. C., \& Macintyre, P. D. 1993. On the measurement of affective variables in Second language learning. Language Learning, 43(2): 157-194.

Kroskrity, P. 2000. Language Ideological Perspectives. In Kroskity, P. (ed.) Regimes of Language (1-34). Oxford: American Research Press.

Lytra, V. and Jǿrgensen, J. N. 2008. Multilingualism and identities across contexts: Cross- disciplinary Perspectives on Turkish-speaking Youths in Europe. Copenhagen Studies in Bilingualism 45. Faculty of the Humanities, University of Copenhagen.

Mba, G. 2011. Overview of Language Policy and Planning in Cameroon. Online: http://www.linguapax.org/fitxer/1181/overview \%20of\%20language\%20policy\%20and\%20planning\%20in\%20Cameroon.pdf retrieved 28/02/2013.

Mbangwana, P. N. 1983. Political language and Orality in African Literature. 3rd Annual International Conference on African Literature and English Language.

Menang, T. 2006. Pidgin English and the Anglophone identity in Cameroon. In Mbangwana, P., Mpoche, K. and Mbuh, T. Language, literature and identity, Cuvillier Verlag, Göttingen,

Germany (227-235).

Mforteh, S. A. 2006. Cultural innovations in Cameroon's linguistic Towel Babel. TRANS. Internet-zeitschrift für kulturwissenschaften. No.16/2005. Online: http://www.inst.at/trans/16Nr/03_2/mforteh16/htm retrieved 25/03/09.

Milroy, J. and Milroy, L. 1998. Authority in Language (3rd ed). London: Routledge.

Morgan, C. 1993. Attitude change and foreign language culture learning. Language Teaching 26: 63-75.

Myers-Scotton, C. 2006. Multiple Voices: An Introduction to Bilingualism. Oxford: Blackwell publishing.

Nkemleke, D. 2008. Manual of Information to Accompany the Corpus of Cameroon English. Department of English. University of Oslo.

Pavlenko, A. 2002. Bilingualism and Emotions. Multilingua 21: 45-78.

Pavlenko, A. 2004. 'Stop doing that, ia komu skazala!': Language Choice and Emotions in parent-child communication. Journal of Multilingual Multicultural Development. 25(2 and 3): 179-203.

Siachitema, A. 1985. Attitudes towards the use of English in Three Neighbourhoods of Lusaka in Language. In Davies, A. (ed.) Education in Africa 1: 201-231.

Schiffman, H. 1997. The study of language attitudes. Handout for Linguistics 540. University of Pennsylvania, Autumn 1997.

Simo Bobda, A. and Mbangwana, P. 1993. An introduction to spoken English, Akoka: university of Ibadan

Thomas, L., Warein, S., Singh, I. Peccei, J. S., Thornborrow, J. and Jones, J. 2004. Language, Society and Power: An Introduction. (2nd ed) London, New York: Routledge.

Weber, J. and Horner, K. 2012. Introducing Multilingualism: A Social Approach. London: Routledge. 